\title{
КОМПАРАТИВИСТИКА
}

УДК 930.85

DOI: $10.17223 / 24099554 / 9 / 1$

\section{Л.Н. Киселева}

\section{ПРОБЛЕМЫ КОНСТРУИРОВАНИЯ И ИЗУЧЕНИЯ ЭСТОНСКО-РУССКОГО КУЛЬТУРНОГО ПРОСТРАНСТВА ${ }^{1}$}

\begin{abstract}
Предпринимается обзор основных факторов, определивших взаимодействие русской и эстонской культур в позднеимперский период (последняя треть XIX - начало XX в.). Основное внимание посвящено негативным последствиям непродуманной языковой политики имперских властей в области образования, проводившейся в Остзейском крае. Жесткая русификация системы образования вступила в противоречие со сложившимися принципами обучения в начальной школе на родном эстонском языке, значительно затруднила прочесс обучения и спровоцировала рост отрицательного отношения общества к русской культуре. В качестве репрезентативной альтернативы насильственной русификации рассматривается программа языкового образования, выдвинутая знаменитым филологом И.А. Бодуэном де Куртене в серии речей и публицистических выступлений 1900-1910-х га.

Ключевые слова: Эстония, Остзейский край, Российская империя, языковая политика, русификация, И.А. Бодуэн де Куртене.
\end{abstract}

При сравнительном изучении культур принято говорить о кульmypнblx связях, подразумевая либо биографические контакты деятелей разных культур, либо переводы с одного языка на другой и их прагматику, либо разного рода воздействия текстов, созданных в рамках одной культуры, на тексты другой и т.п. Мне бы хотелось поставить вопрос по-другому. В результате контактов создается новое культурное пространство - пространство в семиотическом смысле, созданное /создаваемое на пересечении двух культур.

\footnotetext{
${ }^{1}$ Статья написана в рамках проекта IUT34-30 «Ideology of Translation and Translation of Ideology: Mechanisms of Cultural Dynamics under the Russian Empire and Soviet Power in Estonia in the 19-20th Centuries».
} 
Как и всякое культурное пространство, оно существует в особой, метафизической реальности. К нему не применим «материальный» критерий, как к пространству географическому. Его можно определить как «воображаемое сообщество», по аналогии с андерсоновским определением нации [1] - оно конструируется коллективным культурным сознанием и является продуктом культурного строительства. Процесс конструирования осуществляется в текстах, главным образом - вербальных, как устных, так и письменных, и к самому пространству в целом можно применить семиотическое понятие текста [2]. Таким образом, мы полагаем, что тот конструкт, который мы называем эстонско-русским культурным пространством, существует по законам текста, имеет свою поэтику и может исследоваться законами риторики, а его реконструкция и описание осуществляются учеными, изучающими этот феномен. Границы данного текста не совпадают с географическими, государственными, национальными и языковыми границами Эстонии, хотя наиболее отчетливая географически-пространственная прикрепленность связана именно с ней, как бы эта территория ни называлась в прошлом: Estland und Livland, Эстляндская и Лифляндская губернии, Эстонская Республика, ЭССР или как-то иначе. Однако процесс конструирования может осуществляться и изза ее пределов и даже людьми, биографически с ней не связанными. Поэтому это пространство реально, как реальны нации или, например, фольклор; оно имеет даже своих носителей, но принадлежность к нему является актом культурного выбора. Оно имеет свою историю, его границы подвижны; в этом коллективном создании можно выделить индивидуальные голоса, более или менее значимые. Ведущая роль, как мы полагаем, принадлежит здесь литераторам, традиционным лидерам нации, особенно в период национального строительства.

Часть сложностей при реконструкции и изучении эстонско-русского культурного пространства связана со спецификой любого многостороннего комплексного и динамического объекта, а именно с практической неисчерпаемостью фактов и явлений, которые требуют выявления и учета, и, следовательно, - с трудностью перехода от эмпирики к полноценным обобщениям. Вторая трудность заключается в «чувствительности» и политизированности темы. Проблема межкультурных контактов приграничных культур неразрывно связана с проблемами межнациональных отношений, национальных стереотипов и исторических травм, и конфликт интересов практически неизбежен. 
Исторически на территории Эстонии сосуществовали три основные культуры: немецкая, эстонская и русская, и это сосуществование, в силу все тех же исторических причин, не было мирным. Хотя эстонцы вплоть до советского периода всегда составляли около 90\% населения, до XX в. доминирующей была культура прибалтийских (остзейских) немцев, которые составляли всего лишь 4-5\% жителей, но вплоть до 1918 г. являлись основными землевладельцами и практическими хозяевами края. В публичной сфере и образовании до конца XIX в. доминировал немецкий язык. Образование было доступно лишь очень малому числу выходцев из эстонского крестьянства, причем его результатом часто оказывалось онемечивание. Эстонская культура до середины XIX в. была культурой народной, само слово «эстонец» появилось лишь в 1857 г., до этого самоназванием эстонцев было - в дословном переводе - «люди земли», т.е. мужики. Однако национальное пробуждение, начавшись в середине XIX в., очень быстро привело к формированию образованного класса эстонцев и созданию высокой национальной культуры. Русские составляли в крае еще меньший процент, чем немцы (примерно 3-4\%). В основном это были староверы в Причудье, переселившиеся на западный берег Чудского озера и закрепившиеся здесь с конца XVII в. Так называемые «образованные» русские (чиновники, военные, духовенство) с начала имперского периода присутствовали скорее как явление временное и маргинальное, с открытием Императорского Дерптского университета (1802) - все более и более, но даже в период русификации на рубеже XIX-XX вв. их процент был невелик. Поэтому можно сказать, что взаимодействие эстонской и русской культур происходило не на местном, а на гораздо более широком и общем уровне, и это имеет принципиальное значение для постижения эстонско-русского культурного пространства.

Во-первых, с середины XIX в. началась интенсивная миграция эстонцев во внутренние губернии Российской империи. Это происходило из-за острой нехватки земли, так что в конце века за пределами Эстонии проживало примерно 100 тыс. эстонцев (и это при их общей численности примерно в 900 тыс.), из них в Петербурге - около 10 тыс., в основном рабочих. В 1917 г. их было уже 50 тыс. В столице возникли эстонские школы, церкви, культурно-просветительные общества, газеты [3-5]. 
Во-вторых, эстонцы, получившие гимназическое образование на русском языке в период русификации, устремились в высшие учебные заведения обеих столиц и других городов империи, где возможностей для самореализации и трудоустройства было больше, чем на малой родине. В 1915 г. в высших учебных заведениях Петербурга обучалось около 300 эстонцев, примерно столько же в Москве и других городах, а в Тарту в то же время их училось 364 [6. С. 282]. К концу имперского периода образовался значительный слой эстонской интеллигенции [7], прекрасно владевшей русским языком и находившейся, так сказать, внутри русской культуры. Однако это не означало, что отношение к империи и к ее титульной нации было положительным. И совсем не русская культура была тому причиной.

Если в первый период национального пробуждения лидеры эстонского национального движения ориентировались на защиту от гнета прибалтийских немцев со стороны центральных властей, то период русификации изменил положение. Здесь мы сталкиваемся с ситуацией, когда намерения имперских властей пришли в полное противоречие с результатами их политики, оказавшейся гибельной для них самих. Идея заключалась, как убедительно показал А. Миллер, в интеграции имперских окраин в единую и неделимую Россию [8]. В остзейских губерниях это был шаг к ликвидации так называемого остзейского права, т.е. немецкого господства в крае, что стало особенно актуальным после образования в 1871 г. Германской империи и усиления сепаратистских тенденций - стремления к воссоединению «восточных немецких провинций», т.е. прибалтийских российских губерний, с исторической метрополией. Однако то, что должно было быть направлено против прибалтийских немцев, ударило по эстонцам и наложило неизгладимый отпечаток на формирование эстонско-русского культурного пространства.

Здесь проявилась даже не злая воля, а извечный бюрократический принцип «унификации», не говоря о стремлении ретивых исполнителей выслужиться перед начальством. Вопреки логике и здравому смыслу было решено перевести всю школу, начиная с начальной, на русский язык обучения. Сказались и некомпетентность, и полное непонимание местной ситуации.

В отличие от большинства крестьянского населения России, эстонские крестьяне в своем большинстве были грамотными (неграмотных эстонцев к концу XIX в. было примерно 5\%, а среди русских таковые 
составляли около 70\%). Причина этого заключалась не в культуртрегерских усилиях прибалтийских немцев, которые в своем большинстве отнюдь не стремились просветить туземцев, а в требованиях лютеранской церкви. Как известно, для любого лютеранина, независимо от статуса, существует условие обязательной грамотности для прохождения конфирмации, поэтому создание начальных школ для эстонских крестьянских детей, где обучение шло на родном языке, было неизбежным. Такие школы в Остзейском крае содержались либо помещиками, либо приходами, либо волостными управлениями, и в течение XIX в. их число постоянно увеличивалось. Таким образом, до момента перевода начальной школы на русский язык эстонцы имели возможность получать начальное образование на родном языке. Эстонских гимназий не существовало, и от перевода гимназий на русский язык эстонцы, в отличие от прибалтийских немцев, только выиграли [9. С. 335]. Если бы гимназический этап обучения на русском языке надстраивался на прочной базе начального обучения на родном языке, можно было бы говорить о формировании ситуации более или менее органичного культурного двуязычия. Русский язык образования становился бы посредником в приобщении эстонцев к европейской культуре, а родной язык развивался бы в культурных обществах, народных хорах (их сеть к 1890-м гг. была очень развита и давала отличные результаты), с помощью эстонской прессы, книг и пр. Более отдаленной целью национальных лидеров стала бы, конечно, культурная автономия (такое требование и было выдвинуто после 1905 г.). Но для реализации такого пути нужна была иная страна, иная государственная стратегия.

Как известно, Александр III позиционировал себя как «русского» императора и воспринимал Российскую империю как русскую. Из этого вытекало, что все подданные должны были чудесным образом (и в возможно более короткий срок) преобразиться в русских, хотя прямая задача ассимиляции и насильственного перевода в православие не ставилась. Однако знание государственного языка становилось обязательным, и все школы (в том числе и частные) должны были перейти на русский язык преподавания. Никто не думал о том, что насильственная и бессмысленная русификация начальной школы 
подорвет возможность умственного и культурного развития учащихся на родном языке ${ }^{2}$. Русский язык сделался репрессивным средством, поскольку интересовал власти как проводник государственной идеологии, средство воспитания лояльности и подавления национального самосознания, а не как проводник русской культуры.

Сами по себе правительственные постановления были на первых порах более мягкими, чем их воплощение на практике. Вначале, с 1886-1887 гг., предполагалось ввести преподавание по-русски только некоторых предметов и лишь на третьем году обучения, а обучение чтению, письму, Закону Божию, церковному пению оставить на родном языке. Но и для такого небольшого преобразования не хватало учителей, знающих русский. Начались увольнения тех, кто русским языком не владел, часто увольнялись хорошие педагоги, а на их место принимали юношей (как было оговорено в циркуляре - не младше 17 лет!) без всякой предварительной подготовки. Разумеется, это сразу же отразилось на качестве знаний учеников. Но главное - инспекторы, в нарушение правительственного постановления, стали требовать немедленного перевода всего преподавания на русский язык [9. С. 330]. В результате семилетних крестьянских детей, ни слова не знавших по-русски и русского языка часто вообще не слышавших, сразу сажали за русскую книгу. В 1893 г. было издано распоряжение, запрещавшее ученикам говорить с учителем и между собой в стенах школы на родном языке. За нарушения наказывали строго, ретивые инспекторы устраивали слежку, учеников побуждали доносить друг на друга. Создавалась невыносимая атмосфера, которая способствовала долбежке, отуплению детей и уж, конечно, не вызывала любви ни к русскому языку, ни к русской власти. Учащимся начальной школы приходилось преодолевать огромные и совершенно не оправданные трудности на пути к просвещению. Именно поэтому впоследствии школа, в том числе и гимназия, вспоминалась эстонцами не только без удовольствия, но с чувством отторжения и враждебности.

Такова была ситуация, сложившаяся в конце XIX - начале XX в. Раздавались ли голоса, протестовавшие против такой правительственной политики? Безусловно. И важно, что они исходили как раз из большого русского культурного пространства. Мы кратко коснемся лишь одного примера - позиции великого лингвиста И.А. Бодуэна

\footnotetext{
${ }^{2}$ О горестном опыте преподавания в таких условиях в латышской школе см.: [10].
} 
де Куртене (1845-1929). Он был одним из тех, кто не только протестовал, но и предлагал конкретную программу, разрабатывал теоретические основы разумной национальной политики. Как поляк, на себе испытавший давление российской политики, и как профессор немецкого Дерптского университета в 1883-1893 гг. [11], глубоко проникший в ситуацию Прибалтийского края, он посвятил весь свой общественный темперамент борьбе за языковое и культурное равноправие национальных меньшинств. Мне уже приходилось писать о замечательной речи Бодуэна [12], тогда профессора Петербургского университета, произнесенной им в Тарту на праздновании 100-летнего юбилея Дерптского / Юрьевского университета в 1902 г. [13], причем на немецком языке - в знак протеста против того, что местным немцам было запрещено выступать по-немецки. Однако главная мысль речи, как и всех работ Бодуэна по национальному вопросу, не встретила сочувствия ни со стороны умиленной оппозиционным жестом аудитории, которой он напомнил, что университет стоит на эстонской земле, ни у российских властей, которые неизменно препятствовали публикации такого рода его сочинений. За одно из них «Национальный и территориальный признак в автономии» (1913) [14] он был по решению петербургского суда посажен в «Кресты» и едва не поплатился двухлетним заключением в крепости. Только энергичный протест собратьев-академиков, заявленный по инициативе А.А. Шахматова, и заступничество президента Академии - великого князя Константина Константиновича - подвело 69-летнего знаменитого профессора, академика не только российской, но и всех славянских академий, действительного статского советника и многих орденов кавалера, под амнистию: Николай II сократил срок до трех месяцев, которые Бодуэн уже отсидел.

Главным тезисом всех работ Бодуэна де Куртене по национальному вопросу становятся идея равноправия всех наций и отказ от идеи господствующей нации (как и господствующего языка): «...признание всем национальностям и племенам одинаковых прав в пределах их культурного развития и национального самосознания. Численное преобладание той или другой национальности не дает ей права на господство и первенствующую роль» [15. С. 11]. Он почти дословно повторяет в нескольких текстах тезис: «Долой лозунги "Россия для русских", “Польша для поляков". Россия для всех, кто в ней живет, Польша для всех, кто в ней живет» [Там же. С. 7]. В другом месте он 
пишет то же о Литве, о балтийских провинциях и тут же останавливается на имперском парадоксе, когда дискриминируемым порой оказывается «национальное большинство»:

До чего доводит отсутствие гарантий для большинства, мы видим хотя бы в Прибалтийском крае, где незначительный процент немецких баронов и рыцарей, вместе с немецкою интеллигенцией, властвовал исключительно и подавлял всякую политическую жизнь у фактических рабов, латышей и эстонцев [15. С. 7].

Вместе с тем для Бодуэна главным оказывается даже не борьба за права наций, а право выбора, и в этом смысле сама национальная принадлежность, с его точки зрения, не может считаться обязательной. То же относится и к языку. Человек имеет право выбора языка (или языков), который он считает родным (родными). Бодуэн де Куртене неоднократно декларировал право каждого человека обучаться в школе на своем родном языке. Понятно, что это приходило в полное противоречие с имперской школьной практикой. Но не менее важным был для него и отказ от любого обязательного и навязываемого сверху языка. Эту мысль он выдвигает, в частности, в статье «Значение языка как предмета изучения», опубликованной в журнале «Русская школа» в 1906 г. Бодуэн пишет:

По-моему, с точки зрения здравой педагогики, в каждой школе должно быть признано обязательным, как средство развития ума, изучение одного только языка, т.е. того языка, который ученики приносят с собою в школу и который вместе с тем должен быть преподавательским языком. Ни один другой язык не должен быть обязательным. Но зато надо устроить так, чтобы всем ученикам дана была возможность усваивать практически и затем делать предметом наблюдения и внутреннего опыта следующие категории языков [16. С. 76].

Далее он перечисляет русский (с оговоркой - «при нынешних условиях»), «более распространенные языки европейско-американские: немецкий, французский, английский и, по мере возможности, итальянский», добавляя к ним эсперанто, а также местные языки - языки жителей данной области, а также латинский и греческий [16. С. 77]. Понятно, что как филолог Бодуэн не заботится о вопросах финансирования такой школы - вопрос о материальных средствах явно принадлежит здесь к числу утопических. 
Выдвигая свою программу, Бодуэн де Куртене решительно отвергает идею «братства народов», взаимной любви как движущей силы общественных перемен. Любая программа, по его мысли, должна быть основана на чувстве справедливости и взаимного интереса «альтруистическом утилитаризме», «утилитаризме с точки зрения блага родной страны, родной области, родной местности». Именно поэтому он не теряет надежды на то, что ради своего же блага правительства и народы разных стран откажутся от самовозвышения (от любого «национального хвастовства», как он это называет) и подавления других.

Бодуэн оказался пророком, когда писал в 1913 г.:

Гибель государства, в котором беззаконие и неумолимая жестокость совершают победное торжественное шествие по всей стране, государства, в котором хронические и возведенные в правило нарушения этических заповедей и просто преступления не только не осуждаются и не презираются, но, напротив того, превозносятся как подвиги и щедро награждаются, гибель такого государства ни в ком не вызовет сожаления [14. С. 83-84].

Таким образом, выдающийся русский ученый последовательно обосновывал идею равноправия всех языков и наций, права, в том числе и эстонцев, на развитие своей национальной культуры и обучение на своем языке. Его работы, изданные в центральной России, с удовлетворением читали и деятели эстонского национального движения. Фактически Бодуэн де Куртене предложил единственно возможный путь продуктивного взаимодействия разных культур, в том числе и путь выстраивания эстонско-русского культурного пространства. Возвращаясь к трудностям его изучения, о которых было сказано выше, подчеркнем, что исследователь, взявшийся за его реконструкцию, должен смотреть на свой объект по меньшей мере с двух точек зрения, вооружиться двойной оптикой и еще более тщательно, чем при подходе к одной культуре, рефлектировать собственную позицию и всеми доступными способами стремиться избежать политической ангажированности.

\section{Лuтература}

1. Андерсон Б. Воображаемые сообщества: Размышления об истоках и распространении национализма. М. : КАНОН-пресс-Ц, Кучково поле, 2001. 288 с. 
2. Лотман Ю.М. Семиотика культуры и понятие текста // Лотман Ю.М. Избранные статьи. Таллин : Александра, 1992. Т. 1: Статьи по семиотике и типологии культуры. С. 129-132.

3. Pullat $R$. Lootuste linn Peterburi ja eesti haritlaskonna kujunemine kuni 1917. Tallinn : Estopol, 2004. $504 \mathrm{lk}$.

4. Исаков С.Г. Петербург в истории эстонской культуры // Радуга. 1993. № 3. C. $62-71$.

5. Исаков С.Г. Эстонские общества и организации в Петербурге в XIX - первые годы XX в. и их культурно-просветительная деятельность // Россия и Балтия. Остзейские губернии и Северо-Западный край в политике реформ Российской империи. 2-я половина XVIII - XX в. М. : ИВИ РАН, 2004. С. 156-187.

6. Tartu Ülikooli ajalugu / Koost. K. Siilivask. Tallinn : Eesti Raamat, 1982. Kd. 2: 1798-1918. $430 \mathrm{lk}$.

7. Karjahärm T., Sirk V. Eesti haritlaskonna kujunemine ja ideed. 1850-1917. Tallinn : Eesti Entsüklopeediakirjastus, 1997. $423 \mathrm{lk}$.

8. Миллер А. Империя Романовых и национализм : эссе по методологии исторического исследования. М. : Новое литературное обозрение, 2008. 248 с.

9. Elango A., Laul E., Liim A., Sirk V. Eesti kooli ajalugu. Tallinn : Teaduste Akadeemia Kirjastus, 2010. Kd 2. $774 \mathrm{lk}$.

10. Золотарев С. Десять лет в прибалтийской школе // Эсты и латыши, их история и быт : сб. статей / под ред. М.А. Рейснера. М. : Тип. И.И. Иванова, 1916. С. 244-259.

11. Бодуэн де Куртене И. Автобиография // Биографический словарь профессоров и преподавателей Императорского Юрьевского, бывшего Дерптского, университета за сто лет его существования (1802-1902) / под ред. Г.В. Левицкого. Юрьев : Тип. К. Матиссена, 1903. Т. 2. С. 483-493.

12. Kisseljova L. Eine Rede, ein Aufsatz, eine Lebensaufgabe - das Engagement und die Haltung von Baudouin de Courtenay // Valerio: Das Magazin der Deutsche Akademie für Sprache und Dichtung. Göttingen : Wallstein, 2017. Bd. 19: Zum Beispiel Estland. Das Land und die vielen Sprachen. S. 27-39.

13. Бодуэн де Куртене И. Дерпт - Юрьев (К вопросу о равноправии) // Эсты и латыши, их история и быт : сб. статей / под ред. М.А. Рейснера. М. : Тип. И.И. Иванова, 1916. C. $260-272$.

14. Бодуэн де Куртенэ И.А. Национальный и территориальный признак в автономии. СПб. : Тип. М.М. Стасюлевича, 1913. 84 с.

15. Бодуэн де Куртене И. Проект основных положений для решения польского вопроса. СПб. : Кн. маг. «М.О. Вольф» и «Труд», 1906. 16 с.

16. Бодуэн де Куртене И.А. Значение языка как предмета изучения // Русская школа. 1906. № 7/8, июль-август. С. 69-79.

\section{THE PROBLEMS OF DESIGNING AND STUDYING THE ESTONIAN- RUSSIAN CULTURAL SPACE}

Imagologiya i komparativistika - Imagology and Comparative Studies, 2018, 9, pp. 516. DOI: $10.17223 / 24099554 / 9 / 1$

Ljubov N. Kisseljova, University of Tartu (Tartu, Estonia).

E-mail: ljubov.kisseljova@ut.ee

Keywords: Estonia, Ostsee Territory, Russian Empire, language policy, russification, I.A. Baudouin de Courtenay. 
The article is written in the framework of the project IUT34-30 "Ideology of Translation and Translation of Ideology: Mechanisms of Cultural Dynamics under the Russian Empire and Soviet Power in Estonia in the 19th - 20th Centuries".

The article reviews the main factors that determined the interaction of Russian and Estonian culture in the late imperial period (the last third of the 19th - the beginning of the 20th centuries).

Until the twentieth century, the dominant culture in Estonia was the culture of the Baltic (Ostsee) Germans, who amounted to only 4-5\% of the population, but were still the main landowners and practical masters of the region. Estonian culture was a folk culture, but the national awakening, which began in the middle of the 19th century, very quickly led to the formation of an educated class of Estonians and to the creation of a high national culture. One of the channels of its formation was the introduction of Russian culture in the process of training in gymnasiums and higher educational institutions of the country, mainly in the capital. A turning point in the organic formation of the Russian-Estonian cultural space occurred in the last third of the 19th century.

The article describes the negative consequences of the ill-conceived language policy of the imperial authorities in the field of education in the Ostsee Territory during this period. Rigid Russification of the education system came into conflict with the established principles of education in primary school in the native Estonian language, significantly hampered learning and provoked the growth of a negative attitude of society towards Russian culture.

A representative alternative to violent Russification is considered, which is the program of language education put forward by the famous philologist I.A. Baudouin de Courtenay in a series of speeches and journalistic performances of the 1900s-1910s. The main thesis of all his works is the idea of the equality of all nations and the rejection of the idea of the dominant nation and the dominant language. At the same time, Baudouin de Courtenay finds the right to choose rather than struggle for the rights of nations crucial; in this sense nationality as such, from his point of view, can not be considered mandatory. The same applies to language. One has the right to choose the language (or languages) that one considers native. Baudouin de Courtenay proposed the only possible way of a productive interaction between different cultures, including the way of building the Estonian-Russian cultural space.

\section{References}

1. Anderson, B. (2001) Voobrazhaemye soobshchestva: Razmyshleniya ob istokakh $i$ rasprostranenii natsionalizma [Imagined communities: Reflections on the origins and spread of nationalism]. Translated from English. Moscow: "KANON-press-TS", "Kuchkovo pole".

2. Lotman, Yu.M. (1992) Izbrannye stat'i [Selected articles]. Vol. 1. Tallin: Aleksandra. pp. $129-132$.

3. Pullat, R. (2004) Lootuste linn Peterburi ja eesti haritlaskonna kujunemine kuni 1917 [The City of Hope Petersburg and the Estonian Armed Forces until 1917]. Tallinn: Estopol.

4. Isakov, S.G. (1993) Peterburg v istorii estonskoy kul'tury [Petersburg in the history of Estonian culture]. Raduga. 3. pp. 62-71. 
5. Isakov, S.G. (2004) Estonskie obshchestva i organizatsii v Peterburge v XIX - pervye gody XX v. i ikh kul'turno-prosvetitel'naya deyatel'nost' [Estonian societies and organizations in Petersburg in the 19th - first years of the 20th centuries and their cultural and educational activities]. In: Chubar'yan, A.O. (ed.) Rossiya i Baltiya. Ostzeyskie gubernii i Severo-zapadnyy kray v politike reform Rossiyskoy imperii. 2-ya polovina XVIII - XX v. [Russia and the Baltics. Ostsee provinces and the Northwest Territory in the policy of reform of the Russian Empire. The second half of the 18th - 20th centuries]. Moscow: IWI RAS.

6. Siilivask, K. (ed.) (1982) Tartu Ülikooli ajalugu [History of Tartu University]. Vol. 2. Tallinn: Eesti Raamat.

7. Karjahärm, T. \& Sirk, V. (1997) Eesti haritlaskonna kujunemine ja ideed. 1850-1917 [Formation and ideas of Estonian intelligence. 1850-1917]. Tallinn: Eesti Entsüklopeediakirjastus.

8. Miller, A. (2008) Imperiya Romanovykh $i$ natsionalizm: Esse po metodologii istoricheskogo issledovaniya [Romanov's Empire and Nationalism: An Essay on the Methodology of Historical Research]. Moscow: Novoe literaturnoe obozrenie.

9. Elango, A., Laul, E., Liim, A. \& Sirk, V. (2010) Eesti kooli ajalugu [History of the Estonian School]. Vol. 2. Tallinn: Teaduste Akadeemia Kirjastus.

10. Zolotarev, S. (1916) Desyat' let v pribaltiyskoy shkole [Ten years in the Baltic school]. In: Reysner, M.A. (ed.) Esty i latyshi, ikh istoriya i byt [The Aesti and the Latvians, their history and way of life]. Moscow: Tipografiya I.I. Ivanova.

11. Baudouin de Courtenay, I. (1903) Avtobiografiya [Autobiography]. In: Levitskiy, G.V. (ed.) Biograficheskiy slovar' professorov i prepodavateley Imperatorskogo Yur'evskogo, byvshego Derptskogo, universiteta za sto let ego sushchestvovaniya (18021902) [The biographical dictionary of professors and teachers of the Imperial Yuriev, former Dorpat, University for a hundred years of its existence (1802-1902)]. Vol. 2. Yuriev: Tipografiya K. Matissena.

12. Kisseljova, L. (2017) Eine Rede, ein Aufsatz, eine Lebensaufgabe - das Engagement und die Haltung von Baudouin de Courtenay [A speech, an essay, a life's work - the commitment and attitude of Baudouin de Courtenay]. Valerio: Das Magazin der Deutsche Akademie für Sprache und Dichtung. 19. pp. 27-39.

13. Baudouin de Courtenay, I. (1916) Derpt - Yur'ev (K voprosu o ravnopravii) [Dorpat Yuriev (On the issue of equality)]. In: Reysner, M.A. (ed.) Esty i latyshi, ikh istoriya $i$ byt [The Aesti and the Latvians, their history and way of life]. Moscow: Tipografiya I.I. Ivanova.

14. Baudouin de Courtenay, I.A. (1913) Natsional'nyy $i$ territorial'nyy priznak $v$ avtonomii [National and territorial features in an autonomy]. St. Petersburg: Tipografiya M.M. Stasyulevicha.

15. Baudouin de Courtenay, I. (1906) Proekt osnovnykh polozheniy dlya resheniya pol'skogo voprosa [Draft guidelines for resolving the Polish issue]. St. Petersburg: Kn. mag. "M.O. Vol'f" i “Trud".

16. Baudouin de Courtenay, I.A. (1906) Znachenie yazyka kak predmeta izucheniya [The importance of language as an object of study]. Russkaya shkola. 7/8. July-August. pp. 69-79. 